\title{
The Strategy of Talent Localization in Multinational Corporations
}

\author{
Linjie Li \\ School of International Business \\ Southwestern University of Finance and Economics, Chengdu 611130, China \\ E-mail: 1xin111107@sina.com \\ Xing Wang \\ School of International Business \\ Southwestern University of Finance and Economics, Chengdu 611130, China
}

\begin{abstract}
With China's accession to WTO, a large number of multinational companies enter into Chinese market. It's necessary for multinational Corporations to carry out the the Strategy of Talent Localization. The localization of talents is propitious to eliminate the cultural barriers in cross-border operations, and save the Economic cost as well. However, there are also some problems in the process of localization of multinational talent. This article mainly discuss some of the problems of the the localization of talents, aiming to find some suitable solutions.
\end{abstract}

Keywords: Multinational corporations, Localization, Talent

\section{Introduction}

As the furtherance of the worldwide economic integration and regional blocs, the internationalization of business has become an irreversible trend. The accelerated pace of China's WTO accession, making the multinational companies in China face an unprecedented opportunities for development, but they also face fierce competition for market competition as well. Many strong and powerful multinational corporations have made new strategies to increase investment in China, including expansion, mergers, brand enterprises, enhance the level of branches, develop technology, and so on. But finally, it depends on the talent to achieve these goals. Given the worldwide shortage of key talent, the original talent allocation strategy can not adapt to the new development needs, so we must make strategic adjustments. Many multinational companies have the talent-"localization" as a long-term strategic goals.

\section{The necessity for Talent Localization in Multinational Corporations}

From the phenomenon that a number of multinational companies have to implement the strategic of Talent Localization, we can see that the necessity for Talent Localization is obvious. Talent localized not only adapted to the needs of cultural differences in different countries, while also reducing the economic cost to which meet the needs of multinational corporations.

\subsection{The needs for cultural differences}

The essence of talent localization is cross-cultural management, which means that as the foreign branches of the host country implement management, they need to not only keep the advanced management mode from their home countries, but also use the local talent to adapt to the local environment ,so as to find new methods to manage and minimize the local constraints, aiming to be successful. When multinational corporations contact Management methods, always they will be faced with the different culture, which is radically with their mother culture, as well as the different values, thinking and all kinds of people determined by this culture. Cultural conflicts will adversely affect multinational corporations in many aspects, such as inefficient management decisions, unified corporate objectives, lacking of enterprise cohesion, a substantial increase in management fees, etc. all these will increase the difficulty of multinational operations, and may even lead to the failure of multinational enterprises. As the American scholar David • A • Felix said: "Generally the failure of large multinational companies, always because of the ignor of cultural differences --- ignoring basic or subtle understanding of the results." Thus, managers of multinational companies need to address not only the general organizational structure, capital investment, investment income and other issues, more importantly, to resolve the various contradictions and conflicts, coordination cultural differences in cross-cultural conditions, to promote the effectiveness of human resource output. 


\subsection{The need for economic cost}

The conduction of the strategy talent-Localization have significant influence for multinational companies to reduce the cost.

In normal circumstances, a management staff who is sent abroad must pass through the long period of in-depth training of the relevant host country company. At the same time, these expatriates leave the familiar way of life, to a country with relatively unfamiliar economic and backward technological so the company must pay a fee to compensate for the psychological costs, technology costs of aging, and subsidies from the home country and host countries of Inter travel. These expenditures are necessary, and reasonable. But this kind of train greatly increase the cost of management compared to domestic enterprises. Talent localization help multinational companies reduce the high cost of cross-border operation for the expatriate, as well as promote integration with the local social and cultural, reducing foreign capital and local community crisis mood, conducive to the economic security of the host country and increase employment opportunities

\section{Major problems Multinational corporations faced in the process of localization}

Although there are many benefits of talent localization, now it is develop slowly in the multinational enterprises, and sometimes even drop off. And the major key issues for the process of talent localization in multinationals are as follows:

\subsection{The salaries of foreign staff and local staff are significantly different}

There are statistics show that in the U.S. company, the employee's treatment, compared with their performance, U.S. employees' tend to be high, employees from Hong Kong, Macao and overseas Chinese have moderate salary, but the treatment of local staff is generally low. This difference easily make the local staff psychologically imbalance, thus affecting the enthusiasm. Such sentiments will cause difficulties if they are reflected into the enterprise's management, and even lead to the company's loss of talent, impeding the process of localization .

\subsection{Lacking of international talent in the local labor market}

Multinational companies have already felt the problems of local talent, lacking of international talents in local market and the low international level, thus making the talent localization strategy of some multinationasl shake talent localization, especially the qualified talent localization, people must poses the following qualities:

(1) Have the perspective from a strategic with the overall situation.

(2) With skilled management skills and excellent knowledge.

(3) Operation with Chinese and international market experience and implementation of enterprise mergers, re-experience.

(4) Proficient Foreign language level and the ability to be good at dealing with Headquarters .Motorola is in the earliest advocates for localization of the Western multinational companies. But now, they are re-deployed to replace expatriate managers who had been "localized". why? Faced with the strong pressure from Nokia and Ericsson, the American company found it could not find a competitive talent in the China. It cost much to Employee foreign managers, but the blind localization has underestimated negative impact on the business.

2.3 Competition between multinational companies and that between transnational corporations and local enterprises increased, and the most important resource to support the development of multinational companies is the qualified personnel

As a serious shortage of high-level talent, there is an intense competition for qualified personnel, competition for talent between all transnational corporations. They compete to attract a large number of talent such as innovative technical developers, talent who is familiar with the Chinese market and Intercommunication Chinese and Western management expertise, as well introduce a series of strategies and tactics, such as providing high returns, increased scientific research, to develop staff development programs. Meanwhile, the famous domestic enterprises have joined into the competition for talent among them. The First enterprise recognizing the importance of domestic talent, and compete with foreign companies for that is Lenovo. On October 1999, it corporate with the Ministry of Education National Career Guidance Centre of college graduates, and launched the "Lenovo cross-century-find-talent" programes, in order to attract outstanding students in college to join in. As the War for talent intensifies, the investment multinational corporations put in to attract talent and retain talent increases. it will pay higher salaries and benefits, which will have an adversely affect to the localization process of multinational enterprises. 


\section{The strategy of talent localization in multinationals}

Localization of multinational talent has become a common phenomenon worldwide, although there are problems, the trend is irreversible. MNCs, through a series of strategies, use their people where branches locate, to vigorously promote the localization of human resources to effectively reduce costs, expand market, and obtain high profits.

\subsection{Coordination of the cultural differences within the company.}

The existence of cultural differences is an objective phenomenon, no one can avoid. For managers, the key point is how to cross barriers of cultural differences, gradually establishing the shared values and business concept by combination of points in the two cultures. Different cultures have different values, people of their country always be pride with their culture, make it orthodox, and have the point that the demeanor of foreigners is always curious. In fact, the behavior, values we suppose is odd are natural for the people of that country. Therefore, we must eliminate the sense of national superiority as far as possible, understand and respect other country's culture, communication at equal manner. On this basis, find the point to integrate the two cultures, and develop the advantage to establish unity of values, in order to improve staff cohesion and solidarity, to promote the development of enterprises.

\subsection{Increase the investment of talent}

International competition for talent is fierce, the developed countries can take lots of measures such as expanding the talent migration, increasing research investment, providing high returns, improving the education and training conditions to attract and retain students for its large number of multinational companies. Meanwhile, overseas branchs of multinational corporations can also increase research investment, transport personnel to overseas training ,provide generous pay and benefits to attract a large number of host countries high-level talents. In recent years, multinational companies based in China, targeting to China's prestigious universities, mining top talent. IBM, General Electric, Intel, Microsoft, Panasonic, Motorola, Siemens, Unilever and other large companies all set up scholarships, training department and establish libraries for a variety of names at those universities such as Tsinghua University, Peking University, Fudan University, Jiaotong University and other famous institutions to attract top talent to their company .

\subsection{Improve the enterprise's international image, creating an environment to use localized talent}

Multinational enterprises should have long-term goal. Transnational business purely should aim to make profits, there is no doubt about it, but some of them even at the expense of the interests of the host country, obsoleting equipment to foreign countries to extend their service life, transfering high-polluting enterprises to the host country to reduce its pollution, or to evasion tax and transfer pricing to harm the interests of the host country, avoid the host country's laws, even the control of the host country economy. These short-sighted behavior will inevitably affect the image of multinational companies, and is not conducive to long-term development. MNCs should set up the same goal with the host country for cooperation, and from the overall interests, take the needs of both sides into account in order to achieve "win-win" objective. Meanwhile, a large number of multinational companies hire local staff to enter foreign subsidiaries as manager, this methods which reject the practice of ethnic prejudice, will gain the trust of the host country's government and people, which strengthen the company's ability to deal with the host government.

\section{Conclusion}

So as we can see ,the competence for local talents between different corporations recently are increasingly fierce, cause it's really pivotal for a multinational corporation's existence, which requires enterprises taking actions to keep even appeal more local stuffs who are qualified. While now there exist many problems for the localization of talents in the MNCs, it will also be a sweeping trend because that it can make the corporations more efficient and economical.

\section{References}

Bartlett, C. A., \& Ghoshal, S. (1989). Managing across borders: The transnational solution. Boston: Harvard Business School Press.

Beamish, P., (1998). Equity joint ventures in China: Compensation and motivation. Ivey Business Quarterly, 63 1, pp. 67-68.

Bigley, G.A., and Pearce, J.L. (1998). Straining for shared meaning in organization science: Problems of trust and distrust. Academy of Management Review 23 3, pp. 405-421. Full Text via CrossRef | View Record in Scopus | Cited By in Scopus (131). 
Dowling, P. J., \& Schuler, R. S. (1990). International dimensions of human resource management. Boston: PWS-Kent.

Hixon, A.L. (1986). Why corporations make haphazard overseas staffing decisions?. Personnel Administration, 313 , pp. 91-94.

Huselid, M.A. (1994). Documenting HR's Effect on Company Performance. Human Resources Management Journal, 38: 635-72.

Reynolds, C. (1986). Compensation of overseas personnel. In J. J. Famularo (Ed.), Handbook of human resources administration (pp. 56.1-56.22). New York: McGraw Hill.

Stevenson-Yang, A. (1995). Making your Chinese investment work. China Business Review, 22 3, pp. 34-3

Wall Street Journal. (2006). Firms in China Think Globally, Hire Locally. Wall Street Journal, Feb 27 , p. B1. 